This PDF is a selection from an out-of-print volume from the National Bureau of Economic Research

Volume Title: The National Wealth of the United States in the Postwar Period

Volume Author/Editor: Raymond W. Goldsmith

Volume Publisher: Princeton University Press

Volume ISBN: 0-870-14108-2

Volume URL: http://www.nber.org/books/gold62-1

Publication Date: 1962

Chapter Title: Scope and Character of Estimates

Chapter Author: Raymond W. Goldsmith

Chapter URL: http://www.nber.org/chapters/c2070

Chapter pages in book: (p. 8 - 16) 


\section{Scope and Character of Estimates}

No sYsTeM of national accounts can be regarded as complete without balance sheets for the nation and for the main sectors distinguished in the accounts. ${ }^{1}$ No theory of economic fluctuations or growthwhether based primarily on broad statistical aggregates or derived from cross-section studies of behaviorally significant magnitudes-is likely to succeed unless it incorporates stock variables in addition to the flow variables that have constituted the sole tools for constructing earlier theoretical or econometric models. Awareness of this fact is reflected in the stress in the recent literature on the Pigou effect, introduction of stock variables into the consumption function, controversies about the capital-output ratio following its introduction into the discussion by Harrod and Domar, and attempts to dynamize input-output tables by the addition of stock-flow coefficients.

If these assertions are correct-and they would probably find acceptance among the majority of economists-there is urgent need for a set of estimates of economic stocks (real and financial assets, liabilities, and net worth) in about the same detail and of the same quality as the flow data that are now available. Yet very little has been done in developing such estimates. There are no official estimates of stocks of tangible assets with the exception of a few types (e.g., inventories) and of one sector (agriculture). The resources devoted inside and outside the government to work on national wealth statements and balance sheets are trifling compared with those used in the methodological, statistical, and analytical study of flows.

This disparity between the need for comprehensive and detailed information on stocks and the scanty data available in official or other statistics may justify the publication of the annual estimates of national wealth in the postwar decade that are presented here, notwithstanding their methodological and statistical limitations which are pointed out throughout this report. Companion estimates of intangible assets, of liabilities, and of net worth of the main sectors of the economy have also been completed. In conjunction with the estimates of national wealth, they permit the preparation of national and sectoral balance sheets and will be presented and discussed in a forthcoming National Bureau book.

1 See, for instance, National Accounts Review Committee, The National Economic Accounts of the United States: Review, Appraisal, and Recommendations, New York, National Bureau of Economic Research, 1958, p. 112. 
It is to be hoped that comprehensive estimates of national wealth will not again depend upon individual effort, albeit aided in this study by clerical assistance and by the cooperation of some government agencies producing the relevant basic data. The time has come for lifting the derivation of national balance sheets and of national wealth statements to the same level of intensity that for years has been accepted in national income estimation, in flow-of-funds work, and in input-output analysis. This means the organization of a large-scale project, within the government or outside of it, having at its disposal specialists in the different fields of economic statistics who are essential for building up the estimates, and equipped with the facilities and the authority to collect primary data on the many aspects of measurements of stocks where they are now lacking.

It will be years, even under the best circumstances, before an adequate and up-to-date set of stock estimates can be prepared and be carried back far enough to permit the study of long-term trends. Until then theorists, econometricians, and students of national accounts must work with the rough estimates which can now be put together. The set presented here was developed as part of the National Bureau's Postwar Capital Market Study and is intended to continue similar, often still rougher, estimates for the period 1896 to 1945 , published in Volume III of $A$ Study of Saving in the United States, and to supersede the preliminary figures for $1945-49$ in the same publication. ${ }^{2}$ The figures should, however, serve many other purposes, as the earlier estimates of national wealth and national balance sheets apparently have done. ${ }^{3}$

Respect for the presumed needs of one's fellow workers in the field and of the users of the estimates prompts the desire to give full explanation of sources and estimating procedures. The following pages briefly summarize the main methods and sources and-more important-point to a number of conceptual or statistical weaknesses in the figures. A set of annotated tables which permit those interested to follow in reasonable detail every step in the construction of the estimates will be found in Appendix B of this volume. Some material bearing on the reliability of the estimates will be found in Chapter 5 .

The exact scope of tangible assets included in an estimate of national

2 Special Studies, by Raymond W. Goldsmith, Dorothy S. Brady, and Horst Mendershausen, Princeton University Press, 1956.

3 Preliminary figures for some dates after 1949 have been published in Statistical Abstract of the United States (e.g., 1959, pp. 324-325), in Historical Statistics of the United States (196o ed.), and in the Thirty-Seventh Annual Report of the National Bureau of Economic Research (1957, p. 34). These figures should be regarded as superseded by the present estimates, wherever there are differences. 
wealth is not of great importance so long as the figures are shown in sufficient detail to enable each user to isolate or to combine those types of assets that seem best fitted for his analytical purposes. The estimates presented here are based upon a rather broad definition of national wealth and therefore include separate figures-often unavoidably rough-for categories not always covered by estimates of national wealth, such as consumer durables, government civilian structures, military equipment, forests, and subsoil minerals. No figures, however, are shown for a few other categories of tangible assets, because there is no basis for even rough estimates, particularly on an annual basis: for instance, consumers' holdings of semidurable and nondurable commodities, works of art and collectors' items. There is, however, enough evidence about the order of magnitude involved to conclude that they are very small in proportion to total tangible assets of the nation or of major sectors. ${ }^{4}$ The omission of any estimates for the value of three important natural resources (air, sunlight, water) and of human resources, on the other hand, is based both on the unavailability of a basis for calculation, and on the conviction-not shared by all students of this problem-that these items have no place in an estimate of national wealth of an economy where these resources cannot be appropriated and hence have no market price in an economy in which slavery does not exist.

The present estimates constitute essentially a continuation of the series for the period 1896 to 1949 previously published in slightly varying versions. ${ }^{5}$ For reproducible tangible wealth the estimates are derived by the "perpetual inventory" method; the estimates of the stock of each type of reproducible tangible assets are obtained by cumulating the capital expenditures for that type of assets for a number of years equal to the assumed length of the asset's useful life. New capital expenditures, equal to gross expenditures less retirements

4 See Goldsmith, “A Perpetual Inventory of National Wealth," Studies in Income and Wealth, Vol. 14, New York, National Bureau of Economic Research, 1951, pp. $36-38$.

B (1) Ibid.; (2) idem, "The Growth of Reproducible Wealth of the United States of America from 1805 to 1950 ," Income and Wealth of the United States; Trends and Structure, Income and Wealth Series II, International Association for Research in Income and Wealth, London, Bowes and Bowes, 1951; (3) A Study of Saving in the United States, Vol. III, Tables W-1 to W-8.

For discussion of the general approach and of methodological questions, the reader is referred to the first two publications above, and to Goldsmith, "Measuring National Wealth in a System of Social Accounting," Studies in Income and Wealth, Vol. 12, New York, NBER, 1950. A description of the figures for the years before $194^{6}$ will be found in the tables of (2) and (3) above. Detailed estimates for $1945-5^{8}$ are given in the annotated tables of Appendix B of this book. 
during the same period, are used in the estimation of the gross stock and net expenditures, equal to gross expenditures less depreciation in the calculation of the net stock. Three sets of estimates have been prepared for each type of asset, based respectively on (1) original cost, (2) constant (1947-49) cost, and (3) replacement cost; but only the constant and current (replacement) value estimates are shown, since original cost figures are of very limited value for economic analysis. The constant cost estimates are obtained from the original expenditure figures by means of a price index $(1947-49=100)$ appropriate to the type of expenditure. The replacement cost estimates are derived from the constant cost figures by reflation (multiplication of the constant value figures) with the same indexes.

The elements in the calculation of capital stock are shown in the tabulation below. For every type of reproducible asset being distinguished estimates of the nine separate flows are listed in columns 1 and 2, the cumulation and combination of which yield estimates of the six desired concepts of capital stock of column 4 . Here $k$ designates gross capital expenditures; $r$, retirements; $d$, capital consumption allowances; $m$, new capital expenditures; $n$, net capital expenditures; $G$, gross capital stock; and $N$, net capital stock; the one and two bars above the symbols, indicate, respectively, values expressed in constant (1947-49) prices and current (replacement) costs rather than original cost (unbarred); and the subscripts $v$ and $t$ stand for the length of life of an asset and for the date to which the estimate refers.

Capital Capital

Concept and Valuation Expendi- Con- Capital Capital Base

\section{Gross}

Original cost

Gonstant (1947-49) cost

Replacement cost

\section{New}

Original cost

Constant (1947-49) cost

Replacement cost

\section{Net}

Original cost

Constant (1947-49) cost

Replacement cost sumption Formation Stock 
The derivation of the different stock estimates is summarized in the following simple formulas:

$$
G_{t}=\sum_{a}^{t}\left(k_{j}-r_{j}\right)=\sum_{a}^{t} k_{j}-\sum_{a}^{t} r_{j}=\sum_{a}^{t} k_{j}-\sum_{a-v}^{a} k_{j}(a=t-v)
$$

$$
\bar{G}_{t}=\sum_{a}^{t} \overline{g_{j}}=\sum_{a}^{t}\left(g_{j} \pi^{-1}{ }_{j b}\right) \quad\left(g_{j}=k_{j}-k_{j-v}\right)
$$

(3) $\quad \overline{\bar{G}}_{t}=\sum_{a}^{t} g_{j \pi_{t b}}=\bar{g}_{t \pi_{t b}}$

$$
\left(\bar{g}_{j}=k_{j} \pi_{j b}-k_{j-v} \pi_{(j-v) b}\right)
$$

$$
N_{t}=\sum_{a}^{t}\left(k_{j}-d_{j}\right)=\sum_{a}^{t} n_{j}
$$

where $\quad d_{j}=\frac{1}{t} \sum_{j=v}^{j} k$ or $(1-\gamma) N_{j-1}$

$$
\text { (straight line) (declining balance) }
$$

$$
\begin{aligned}
& \bar{N}_{t}=\sum_{a}^{t}\left(\bar{k}_{j}-\bar{d}_{j}\right)=\sum_{a}^{t} \bar{n}_{j} \\
& \overline{\bar{N}}_{t}=\left[\sum_{a}^{t}\left(\bar{k}_{j}-\bar{d}_{j}\right)\right] \pi_{t b}=\bar{N}_{t} \pi_{t b}
\end{aligned}
$$

The subscripts indicate, respectively, the date to which the estimate refers $t$; the beginning of time $o$; the period during which the expenditures were made $j$; the length of life of the asset $v$; and the base period of the price indexes $b$. The symbol $\pi_{j b}$ stands for the price index for period $j$ on the basis of prices in period $b$.

The relationship between the periods for which expenditures are cumulated in deriving gross and net stocks is indicated in the following equations, which are valid for calculation in original cost or constant prices:

$$
\begin{aligned}
G_{t} & =\sum_{0}^{t} g \\
& =\sum_{0}^{t}(k-r) \\
& \left.=\sum_{0}^{t} k-\sum_{0}^{t-v} k \quad \text { (since } r_{t}=k_{t-v}\right)
\end{aligned}
$$




$$
\begin{aligned}
& =\sum_{t=v}^{t} k \\
N_{t} & =\sum_{0}^{t} n \\
& =\sum_{0}^{t} k-\sum_{0}^{t} d \\
& =\sum_{0}^{t} k-\left(\sum_{0}^{t-v} k+a \sum_{t-v}^{t} k\right) \\
& =(1-a) \sum_{t=v}^{t} k
\end{aligned}
$$

(where $a$ is the average ratio of accumulated depreciation to original cost of assets still in the stock, and $\sum_{0}^{t-v} k$ are assets fully written off)

Thus, both gross and net stock estimates require expenditure estimates only for the period $t-v$, which of course varies in length from asset to asset, though the estimates can also be obtained-theoretically-by summing new or net capital expenditures since the beginning of time. (There is no practical point to this alternative since all new or net capital expenditures for periods more than $v$ years ago are zero.)

For nonreproducible and foreign assets no similar standardized method of calculation is available. (None is needed for inventories as these can be estimated directly.) For these assets we must try to find other methods approximating market value in current or constant (1947-49) prices. In the case of nonagricultural privately owned land, the largest component of nonreproducible assets, the estimates are usually based on land-structure value ratios for which some quantitative evidence is available, although its comprehensiveness and accuracy leave much to be desired outside the field of single family homes. For agricultural land, census figures and estimates based on them, both representing close approaches to market value, can be used. For public land, vacant lots, forests, and for all subsoil assets, very rough estimates of presumed market value are all that can now be contrived. ${ }^{\theta}$

\footnotetext{
6 Because of the method of estimation-tying land to the values of structureswhich we are forced to use owing to the paucity of direct data, it is possible that the increases in the values of undeveloped land during the postwar decade have been understated. There are many reports about large relative increases in the value of land of this type, particularly on the outskirts of cities and along highways. Unfortunately no sufficiently systematic and comprehensive investigation appears to have been made to permit a direct estimate of the value of nonfarm land not underlying
} 
The fact that the estimates for most components of reproducible tangible wealth-specifically for structures and equipment--are built up from gross capital expenditure series makes it very difficult to take account of changes of ownership of reproducible tangible wealth that occur among sectors after an asset has come into existence. To do so it would be necessary to have, for each type of asset, figures on the balance of transactions between each pair of sectors, or at least a figure for the net balance of trade for each sector and each type of asset. Such figures generally are not available for either reproducible tangible wealth or for nonreproducible assets. As a result, the estimates presented here for the wealth of individual sectors reflect in most cases a picture of reproducible tangible wealth originally acquired by the different sectors-subject to errors as these figures may be-rather than a record of assets held at a given point of time.

This specific source of error becomes more important as one sector's net acquisition or sale of a given type of tangible assets from or to other sectors becomes larger compared with its original capital expenditures. For sectors as broad as designated here, net balances are probably small compared with original acquisitions, particularly for long periods of time. There have, however, been types of transactions in tangible assets among sectors-apparently dealing mostly with nonreproducible assets-that were relatively substantial and that tended continuously in the same direction. Probably the most important example is the sale of agricultural land by the farm sector to the nonfarm, household, and business sectors. One of the few cases involving reproducible assets and transfers of substantial size, though occurring over a relatively short period, is the sale of government owned plants, equipment, and residences to private business, local governments, and households after World War II. The acquisition of large stockpiles of agricultural and mineral products by the federal government may be regarded as another example, although such transactions are treated here as original acquisitions by the government. Some of these transfers have been taken into account in the estimates, while most of them had to be ignored because no figures were available or because estimation was too time consuming in view of the magnitudes involved.

It thus should be recognized that the estimations of wealth by sector are subject to errors that do not affect estimations of aggregate national

structures. This is a field in which a systematic nationwide investigation is urgently needed. 
wealth or of wealth by type of assets, both of which of course are invariant to changes of ownership among domestic sectors.

There is one problem bearing upon the scope and character of the estimates used in this study which apparently has been disturbing many users of national wealth estimates-the possibility of double counting, which is presumed to be present in particular when the value of government assets, primarily nonreproducible assets such as land, is included in national wealth.

The argument is that to include government assets, such as roads and streets in addition to the value of adjoining private properties already included at market value, constitutes double counting, since part of the market value of those private properties reflects the proximity of roads and streets and other government structures. Hence, it is argued, the value of roads and streets is already implicitly included in the value of the adjoining private properties and must not be added separately to the estimates of aggregate national wealth. It is difficult to accept this argument for reproducible tangible assets if national wealth is regarded as the sum of the market values of all separate tangible assets, or an approximation of market values such as replacement cost. Obviously, the replacement cost of roads and streets, i.e., their original cost of construction adjusted for capital consumption and changes in construction cost, does not differ in any essential way from the replacement cost of other reproducible tangible assets.

The argument, therefore, must be limited to the value of government nonreproducible assets, particularly land. Since the market value of all land, whether privately or government owned, is affected by many factors and in turn affects other components of national wealth, the value of land underlying roads and streets, or more generally of government owned land, cannot be excluded simply because its existence affects the value of adjoining private land. Private structures also affect the value of adjoining private land, but this does not lead to the exclusion of the value of land underlying these structures from national wealth. The value of the land underlying railroad tracks or structures like universities or Rockefeller Center is not excluded from national wealth, although the existence of the structures is likely to affect the value of adjoining properties, and specifically the land element in their values. The fact that many types of government land, including land underlying roads and streets, have no easily ascertainable market value has practical importance, and is a reason for caution in interpreting the estimates. It is not a sufficient reason, however, for 
excluding the value of these types of government land, the more so since such values are often actually ascertained when private land is condemned for government use. ${ }^{7}$

The practical solution of these controversies is the same as that proposed in the case of several other points in dispute. It is to present separate estimates for the disputed items, and then let the users adjust the totals in accordance with their taste, since it is impossible to show in one table figures for all possible concepts of national wealth, let alone to indicate in each case when analysing the figures how the interpretation would be affected if a different concept had been used. In accordance with this principle the values attributed to government owned properties, and to the land underlying them specifically, are shown separately in the aggregate in the text and Appendix A tables and in more detail in the Appendix B tables.

7 So far as actual quantitative relations go, the question whether or not the land under roads and streets should be included separately in an estimate of national wealth and, if so, how its value should be estimated is of secondary importance. The site value of roads and streets does not constitute a separate element in our estimation of the value of all land owned by state and local governments. Howvever, since our estimates are tied to the bench-mark estimate for 1946 ( $A$ Study of Saving in the United States, Vol. III), they implicitly include an allowance for the site value of roads and streets. This value can be put roughly at about 2 per cent of total net national wealth (excluding military assets) in 1946, and at about 1 per cent in $195^{8}$. The importance of the site value of roads and streets is still smaller for gross national wealth. On the other hand, the implicit allowance for the site value of roads and streets is not negligible in comparison with the estimated value of all public land (about one-half in 1946 and two-fifths in $195^{8}$ ) or with the total net wealth of state and local governments. Therefore, it may make a difference whether or not separate allowance is made for the site value of roads and streets. Even in this narrow field it is not likely, however, that any major trends during the postwar period would be affected by the choice between including and excluding the site value of roads and streets. 